\title{
AVALIAÇÃO DA QUALIDADE DOS SERVIÇOS EDUCACIONAIS PRESTADOS POR UMA INSTITUIÇÃO DE ENSINO SUPERIOR (IES)
}

\author{
ASSESSING THE QUALITY OF THE EDUCATIONAL SERVICES \\ PROVIDED BY A HIGHER EDUCATION INSTITUTION (HEI)
}

Recebido em: 07/10/2011 Aprovado em: 21/12/2011

Avaliado pelo sistema double blind review

Editora Científica: Manolita Correia Lima

\section{ALEXANDRE MENDES DA SILVA alex_ams1972@yahoo.com.br UNIVERSIDADE NOVE DE JULHO}

\author{
RAQUEL DA SILVA PEREIRA \\ UNIVERSIDADE MUNICIPAL DE \\ SÃO CAETANO DO SUL
}

\section{RESUMO}

Este estudo desenvolveu-se com o objetivo de verificar a qualidade de cursos superiores de Administração e de Gestão, à luz do artigo $4^{\circ}$, da Resolução ${ }^{\circ}$ 4, de 13 de julho de 2005, onde o Ministério da Educação (MEC) lista as competências definidas para a formação de administradores. Desenvolveu-se uma escala de avaliação com base na qualidade percebida pelos estudantes, lastreada na Resolução supracitada, e realizou-se um levantamento tipo survey, totalizando 629 respondentes, com alunos dos cursos de Administração e de Gestão de uma Instituição de Ensino Superior (IES) de grande porte, localizada no município de São Paulo. Os resultados mostram que as competências exigidas pelo MEc para o curso de Administração não são percebidas integralmente junto aos estudantes por meio dos serviços educacionais oferecidos pela IEs, pois as pontuações ficaram abaixo do score máximo possível.

Palavras-chave: qualidade de serviços; Ensino Superior; Ensino de Administração, servperf.

\section{ABSTRACT}

This study was carried out with the aim of assessing the quality of degree programs in Administration and Management based on article 4 of Resolution $N^{\circ} 4$ of July 13, 2005, in which the Ministry of Education and Culture (MEC) lists the skills that future administrators must have. An assessment scale for this purpose was backed by said Resolution and developed based on the students' perception of the quality. A survey was conducted with students enrolled in Administration and Management degree programs at a large Higher Education Institution (HEI) located in the city of São Paulo, with the number of respondents totaling 629. The results indicate that, since the scores were below maximum, the skills required by the MEC for degree programs in Administration are not being fully imparted to students through the educational services provided by the HEI.

Keywords: quality of services; Higher Education; Administration Education; SERVPERF. 


\section{INTRODUÇÃO}

No atual contexto de competição em nível global, a qualidade na prestação de serviços é considerada importante diferencial e base para o sucesso, sendo uma das mais poderosas tendências que influenciam as estratégias de negócios. Desde a década de 1980, a qualidade em serviços tem sido associada ao aumento da lucratividade, por ser uma importante vantagem competitiva ao gerar a repetição de vendas, a comunicação boca a boca positiva, a lealdade do cliente e a diferenciação competitiva para produtos (FIRDAUS, 2006a).

Muitos serviços definem-se, sobretudo, em função da relação interpessoal a que dão origem. Podem encontrar-se exemplos disso tanto no setor mercantil que prolifera, alimentando-se da complexidade crescente das economias (especialidades muito variadas, serviços de acompanhamento e de aconselhamento tecnológico, serviços financeiros, contabilísticos ou de gestão), como no setor não comercial mais tradicional (serviços sociais, ensino, saúde etc.) (DELORS, I998, p. 90).

No setor educacional, particularmente na educação superior, vê-se a mesma necessidade de se oferecer serviços que superem a concorrência, como forma de sobrevivência da organização neste mercado, que tem se tornado altamente competitivo (sOUKI; NETO, 2007). O sucesso neste setor, portanto, está associado à habilidade das Instituições de Ensino Superior (IES) em fornecer respostas rápidas e acertadas às exigências do estudante, além de desenvolverem a capacidade de serem flexíveis frente às demandas impostas pelo ambiente (soukI; PEREIRA, 2004). Por isso, a percepção da qualidade que os estudantes possuem em relação aos serviços prestados pelas Instituições de Ensino Superior pode influenciar decisivamente suas atitudes e intenções comportamentais, afetando-as positiva ou negativamente (SOUKI, GONÇALVES FILHO; SILVA, 2006). A qualidade percebida pelo estudante refere-se ao julgamento deste sobre a excelência ou superioridade global do serviço educacional. Ou seja, está mais relacionada a um julgamento abstrato do que aos atributos concretos do serviço (ZeITHMAL, I988). 
A tentativa para definir um instrumento de avaliação padronizado e independente de qualquer contexto de serviço em particular estimulou diversas metodologias. Foram criados vários instrumentos de mensuração, sendo que os mais conhecidos são o SERVQUAL (Service Quality) de Parasuraman et al. (1988), e o SERvperf (Perfomance Only), de Cronin e Taylor (1992), que contribuíram para o desenvolvimento do estudo sobre a qualidade em serviços. Todavia, alguns estudos, que usam essas escalas, demonstraram a existência de dificuldades resultantes dos componentes conceituais e teóricos, tanto quanto do componente empírico (FIRDAus, 2006a). Em função dos diferentes níveis de sucesso na aplicação dos instrumentos citados, bem como das particularidades do ensino superior, Firdaus (2006b) argumenta que o desenvolvimento de uma escala exclusivamente designada para essa indústria, em particular, é uma estratégia de pesquisa mais viável.

Entre os campos do conhecimento, que se preocupam com a temática da qualidade de serviços, esta pesquisa está centrada na confluência das áreas de administração, educação e marketing de serviços, uma vez que tem como foco questões relativas à avaliação de serviços educacionais (veludo DE OLIVEIRA; IKEDA, 2006), com base na formação dos administradores de empresas e procura responder à seguinte pergunta: A qualidade do serviço educacional pode ser avaliada com base nas competências individuais exigidas para o exercício da profissão de administrador?

Para responder a esta questão, elaborou-se um estudo exploratório e descritivo, apoiado em um levantamento de opinião, cujo objetivo geral foi o de avaliar o serviço educacional oferecido por uma IEs de grande porte, localizada no município de São Paulo, por meio da utilização de uma escala elaborada a partir da Resolução n ${ }^{\circ}$. 4, de i3 de julho de 2005 (MEC/CNE/ CES, 2005), que lista as competências exigidas para os administradores. A pesquisa também possui dois objetivos específicos: a) identificar o grau de percepção do aluno quanto às competências desenvolvidas no curso, e b) inferir a qualidade do serviço educacional prestado com base na percepção discente.

Para fins de pesquisa, considerou-se que o atributo "competências", apontado pelo MEC, também é aplicável aos cursos de Gestão, que são cursos 
superiores de tecnologia derivados de Administração, com duração de 2 anos, e que são focados em uma área específica científica, privilegiando as aplicações tecnológicas de um campo do conhecimento, e são considerados cursos de graduação plena, tendo seus diplomas validade nacional (CNE/ CES, 200I e CNE/CP, 2002). A classificação na Sinopse Estatística do INEP apresenta esses cursos de forma abrangente, sob a denominação de "Gestão e Administração", sendo que, além do curso de Administração, constavam 28 nomenclaturas diferentes no ano de 2008 . Além disso, também em 2008, existiam 3.207 cursos de Gestão e Administração, sendo I.809 somente de Administração. Naquele ano, foram colocados no mercado de trabalho I39.989 novos profissionais da área, sendo I03.344 administradores.

Este estudo justifica-se pela possibilidade de contribuir com os gestores e coordenadores de cursos, no acesso a informações e análises que possibilitem avaliar o posicionamento dos estudantes em formação, viabilizando o aprimoramento do planejamento das atividades do curso. $O$ foco na perspectiva do aluno reforça a relevância do estudo sob dois aspectos: a) por ser o propósito do trabalho de cooperar para as atividades de formação em Gestão e Administração (COSTA; OLIVEIRA 2008), e b) por estar preocupado em levantar informações e dados sob o ponto de vista discente, ao invés de privilegiar a opinião de docentes e coordenadores, o que é mais comum em pesquisas nesse campo (GODOY et al., 2005).

O artigo foi estruturado da seguinte maneira: após esta introdução, são abordados, como componentes do referencial teórico, a evolução do ensino superior em Administração e Gestão no Brasil e em São Paulo, seguida das competências exigidas para o curso de Administração, a metodologia do estudo, a apresentação dos resultados e a discussão. Ao final, são feitas considerações a título de conclusão do trabalho, seguidas das referências utilizadas. 


\section{REFERENCIAL TEÓRICO}

O ENSINO SUPERIOR EM ADMINISTRAÇÃO E GESTÃONO BRASIL E EM SÃO PAULO

Entre os anos de 1999 e 2008 o ensino superior no Brasil vivenciou forte processo de expansão, privatização e diferenciação, o que demonstra a competitividade no setor de ensino superior, que obriga as IES a melhorarem continuamente seus serviços e processos, para poderem manter seus alunos e atrair novos ingressantes.

Segundo os dados do Ministério da Educação e Instituto Nacional de Estudos e Pesquisas Educacionais (MEC/INEP/DEED, 2008), em I999 existiam no Brasil I.097 IES, sendo 905 particulares, o que correspondia a $82 \%$ do total. Em 2008, o país já contava com 2.252 IES, sendo 2.016 particulares, ou seja, $90 \%$ do total. A expansão total no número de IES, no período que vai de 1999 a 2008 , foi de $105 \%$. No caso do setor privado, a expansão foi de $123 \%$. Nesse mesmo período, o crescimento no número de IES públicas foi precário, com uma variação de $23 \%$ (Tabela I).

Tabela 1 Evolução das IES no Brasil (1999 a 2008)

\begin{tabular}{|c|c|c|c|c|c|c|c|c|c|c|}
\hline \multicolumn{11}{|c|}{$\begin{array}{l}\text { Número de IES, por Orga } \\
\text { Administrativa das IES }\end{array}$} \\
\hline \multicolumn{4}{|l|}{1999} & \multicolumn{4}{|l|}{2008} & \multirow{2}{*}{\multicolumn{3}{|c|}{ Variação }} \\
\hline \multirow{2}{*}{$\begin{array}{l}\text { Unidade da } \\
\text { Federação/ } \\
\text { Categoria } \\
\text { Administrativa }\end{array}$} & \multicolumn{3}{|c|}{ Total Geral } & \multirow{2}{*}{$\begin{array}{l}\text { Unidade da } \\
\text { Federação/ } \\
\text { Categoria } \\
\text { Administrativa }\end{array}$} & \multicolumn{3}{|c|}{ Total Geral } & & & \\
\hline & $\begin{array}{l}\text { Total } \\
\text { Geral }\end{array}$ & Capital & Interior & & $\begin{array}{l}\text { Total } \\
\text { Geral }\end{array}$ & Capital & Interior & Total & Capital & Interior \\
\hline Brasil & 1097 & 409 & 688 & Brasil & 2252 & 811 & 1441 & $105 \%$ & $98 \%$ & $109 \%$ \\
\hline Pública & 192 & 60 & 132 & Pública & 236 & 82 & 154 & $23 \%$ & $37 \%$ & $17 \%$ \\
\hline Privada & 905 & 349 & 556 & Privada & 2016 & 729 & 1287 & $123 \%$ & $109 \%$ & $131 \%$ \\
\hline São Paulo & 356 & 104 & 252 & São Paulo & 537 & 146 & 391 & $51 \%$ & $40 \%$ & $55 \%$ \\
\hline Pública & 38 & 4 & 34 & Pública & 52 & 6 & 46 & $37 \%$ & $50 \%$ & $35 \%$ \\
\hline Privada & 318 & 100 & 218 & Privada & 485 & 140 & 345 & $53 \%$ & $40 \%$ & $58 \%$ \\
\hline
\end{tabular}

Fonte MEC/INEP/DEED (2008). 
A expansão também foi observada em São Paulo. Em 1999, existiam 356 IES, sendo 318 privadas ( $89 \%$ ) e 38 públicas (II\%). Em 2008, o número total de instituições era de 537, sendo 485 privadas (90\%) e 52 públicas (Iо\%). O crescimento do número de IES no estado de São Paulo nesse período foi de $51 \%$, cerca de metade do registrado no país no mesmo período, o que demonstra que a competitividade no Estado de São Paulo é menor que em outras unidades da federação. As instituições públicas, por sua vez, cresceram $37 \%$, e as privadas 53\%. Em 2008, o município de São Paulo contava com I 46 IES, sendo I40 privadas e 6 públicas, representando $29 \%$ das IES presentes no Estado de São Paulo. O crescimento do número de IES na capital de São Paulo foi de $40 \%$ no período analisado (MEC/INEP/DEED, 2008).

O número de cursos de graduação presencial também vem apresentando uma trajetória de incremento nos últimos anos. Em 1999, existiam no Brasil 8.878 cursos de graduação. No ano de 2008 , esse número aumentou para 24.719 cursos de graduação, o que corresponde a um incremento de $178 \%$ no período. Já as Ies particulares tiveram um aumento mais significativo, passando de 5.384 cursos, em 1990, para um total de 17.947 em 2008, o que corresponde a um aumento de $233 \%$ no período (MEC/INEP/DEED, 2008).

Em São Paulo, existiam 2.399 cursos de graduação em 1999 (FAPESP, 200I) e esse número foi ampliado para 6.307 cursos no ano de 2008 (MEC/INEP/ DEED, 2008), um aumento de i63\% no período. Nos cursos de Gestão e Administração também nota-se um grande crescimento (313\%), com o número de cursos passando de 776, em I999, para 3.207 em 2008.

A grande expansão dos cursos de Gestão e Administração é explicada pela facilidade de se estruturar o curso com poucos recursos financeiros, pois não necessita de laboratórios sofisticados e nem de refinamentos tecnológicos (NICOLINI, 2003). Para Bertero (2006), a expansão de cursos de Administração e o crescimento das matrículas nesses cursos são indícios da importância do ensino e da pesquisa nessa área, para a sociedade. A participação dos cursos de Gestão e Administração no universo de cursos superiores oferecidos no Brasil é de I3\% (MEC/INEP/DEED, 2008).

Estima-se também que a quantidade de brasileiros acima de 25 anos que são formados no ensino superior é de II.366.228 pessoas. Esse número 
corresponde a Io,6\% da população de I07.228.564 com idade de 25 anos ou mais (IBGE, 2008; IBGE, 20IO; LEITE, 20IO). A população total do país, de acordo com o Censo 20 Io do IBGE, é de 190.732.694 habitantes.

A expansão no ensino superior também levanta um ponto relevante para o setor e sua demanda, que é a qualidade de ensino nas instituições, principalmente privadas (SAMPAIO, 2000). Nesse sentido, o Exame Nacional de Desempenho dos Estudantes (ENADE) exerce uma fiscalização mais cuidadosa, de modo a garantir que os estudantes não sejam prejudicados (ALL CONSUlTING, 2009). Com o ENADE, busca-se avaliar não apenas a capacidade técnica dos estudantes, mas também verificar se estes adquiriram as competências exigidas para o exercício da profissão escolhida durante seus cursos (VALENTIM et al., 2008). Dentro de uma perspectiva mais ampla, pode-se considerar a avaliação da qualidade do serviço educacional como um "fator de competitividade para organizações e países, valorizando o conhecimento e, por consequência, conferindo cada vez mais importância à avaliação do ensino superior”" (MACCARI; LIMA; RICCIO, 2009, p.I).

Além disso, pensar sobre a avaliação equivale a formular diagnósticos confiáveis e conceber melhorias com o objetivo de aprimorar as IES (MACCARI; LIMA; RICCIO, 2009). Dada a importância desta discussão, a seguir serão abordadas as competências exigidas para os profissionais de Administração.

\section{AS COMPETÊNCIAS NO CURSO DE ADMINISTRAÇÃO}

A palavra "competência" tem sido uma das palavras mais empregadas e, ao mesmo tempo, uma das mais controvertidas no jargão da administração contemporânea. Nas empresas, assim como na academia, "muitos entendem estar tratando da noção de competência, mas, de fato, estão recorrendo a outros conceitos, como os de qualificação, atribuições, performance, desempenho e objetivos" (RUAS, 2003, p.57).

$\mathrm{O}$ autor continua, ao explicar que, nesse ambiente de diferentes entendimentos, um dos poucos aspectos convergentes é o conceito de "recursos de competência", baseado na escola francesa, que relaciona o conceito de competência à sociologia e à economia do trabalho, sendo sustentada em três elementos fundamentais: 
- Saber (conhecimentos): onde o autor cita como exemplo a estratégia empresarial; métodos de pesquisa de mercado; cultura e legislação sobre o consumo de uma região;

- Saber fazer (habilidades): como exemplos são mencionadas a mobilização de grupos no desenvolvimento de projetos; a coordenação de processos de planejamento estratégico e a orientação da equipe para ampliar o relacionamento com clientes; e

- Saber ser/agir (atitudes): em que aparece o reconhecimento dos próprios erros; percepção e identificação de estados de insatisfação da equipe coordenada; bem como a capacidade de avaliar antecipadamente o impacto de iniciativas e medidas junto aos clientes.

Com base nessa lógica, Boterf (1995) explica que houve uma importante revisão da noção de competência: ela não é um estado de formação educacional ou profissional, nem mesmo um conjunto de conhecimentos adquiridos e capacidades aprendidas, mas a mobilização e aplicação dos conhecimentos, habilidades e atitudes em uma situação específica, onde se apresentam condições e restrições próprias.

Ou seja, a noção de competências acarreta uma composição dinâmica entre conhecimentos, habilidades e atitudes, que dependerá das características da situação atual na qual a competência é colocada em ação, sendo por isso algo maior que carrega consigo uma definição do que é necessário fazer para a consecução do objetivo gerencial esperado. Essa noção de competências pressupõe a existência de flexibilidade, aptidão à mudança e adequação às circunstâncias, sendo esses elementos muito apropriados ao contexto econômico atual (RUAS, 2003). Essa abordagem se contrapõe ao tradicional ensino de Administração, acadêmico e tecnicista, que vem sendo criticado por ser demasiado teórico e por apresentar pouca relevância prática, revelando ainda incongruências ao tratar de questões voltadas para a mudança, valores e transdisciplinaridade, e encorajando uma relação com o conhecimento mais passiva do que ativa (DAVEL et al., 2004).

No ensino superior compete às IES a escolha estratégica das competências específicas que deverão ser desenvolvidas visando à consolidação do perfil do egresso pretendido pelo curso e/ou pela habilitação. Essas competências 
específicas dependem, também, da vocação regional onde o curso se encontra, e da organização diferenciada do currículo, constante no projeto pedagógico do curso (ANDRADE; AMBONI, 2002). O desenvolvimento de competências aparece incorporado à Lei de Diretrizes e Bases da Educação Nacional (LDBN) nº 9394/96, em cujas bases o Ministério da Educação (MEC) estabeleceu as orientações que envolvem todos os níveis da educação nacional por meio de diretrizes, parâmetros e referenciais curriculares (NUNES; PATRUS-PENA; DANTAS, 20II). Os autores explicam, ainda, que no ensino superior, em nível de graduação, foram aprovadas as Diretrizes Curriculares Nacional (DCN), que apresentam, entre outros, as competências que devem ser desenvolvidas nos estudantes durante o curso. E que esse também é o caso da Resolução nº .4 , de I3 de julho de 2005, que instituiu as DCN específicas para o curso de Administração (Quadro I).

Godoy et al. (2005, p.5) explicam que, apesar de ser esperado que o estudante que conclua seu curso de graduação em Administração apresente essas competências, existem estudos que apontam obstáculos em relação às metas estabelecidas pelo MEC. As discussões que se estabeleceram, em especial na ANGRAD, indicam "que as escolas apresentam dificuldades na adoção e utilização do modelo de competências na organização e implantação de seus projetos pedagógicos". Todavia, o perfil do egresso do curso de Administração ainda segue as seguintes premissas:

Quadro 1 Resolução nº. 4, de 13 de julho de 2005

I. Reconhecer e definir problemas, equacionar soluções, pensar estrategicamente, introduzir modificações no processo produtivo, atuar preventivamente, transferir e generalizar conhecimentos, e exercer, em diferentes graus de complexidade, o processo da tomada de decisão.

II. Desenvolver expressão e comunicação compatíveis com o exercício profissional, inclusive nos processos de negociação e nas comunicações interpessoais ou intergrupais.

III. Refletir e atuar criticamente sobre a esfera da produção, compreendendo sua posição e função na estrutura produtiva sob seu controle e gerenciamento.

IV. Desenvolver raciocínio lógico, crítico e analítico para operar com valores e formulações matemáticas presentes nas relações formais e causais entre fenômenos produtivos, administrativos e de controle, bem assim expressando-se de modo crítico e criativo diante dos diferentes contextos organizacionais e sociais. 
V. Ter iniciativa, criatividade, determinação, vontade política e administrativa, vontade de aprender, abertura às mudanças e consciência da qualidade e das implicações éticas do seu exercício profissional.

VI. Desenvolver capacidade de transferir conhecimentos da vida e da experiência cotidianas para o ambiente de trabalho e do seu campo de atuação profissional, em diferentes modelos organizacionais, revelando-se profissional adaptável.

VII. Desenvolver capacidade para elaborar, implantar e consolidar projetos em organizações.

VIII. Desenvolver capacidade para realizar consultoria em gestão e administração, pareceres e perícias administrativas, gerenciais, organizacionais, estratégicos e operacionais.

Fonte MEC/CNE/CES (2005).

Internalização de valores de responsabilidade social, justiça, ética profissional; Sólida formação humanística e visão global que o habilite a compreender o meio social, político, econômico e cultural em que está inserido e a tomar decisões em um mundo diversificado e interdependente;

Sólida formação técnica e científica para atuar na administração das organizações e desenvolver atividades específicas da prática profissional;

Competência para empreender ações, analisando criticamente as organizações, antecipando e promovendo suas transformações;

Capacidade de atuar de forma interdisciplinar;

Capacidade de compreensão da necessidade do contínuo aperfeiçoamento profissional e do desenvolvimento da autoconfiança

(ANDRADE; AMBONI, 2002, p.I9).

Esse perfil é denominado de "generalista especializado", ou seja, o egresso formado em Administração deverá ter uma forte especialidade sem desconhecer as implicações do que faz para a organização como um todo (ANDRADE; AMBONI, 2002). E para consolidar tal perfil, os cursos de graduação em Administração devem prever o desenvolvimento das competências instituídas pelo meC na Resolução n ${ }^{\circ}$. 4, de $\mathrm{r} 3$ de julho de 2005 .

Fonseca et al. (2007) distinguem as competências em dois tipos: competências transversais e competências técnicas. As competências transversais são as orientadas para o desenvolvimento pessoal, social e relacional, segundo uma perspectiva de mobilidade social e de qualidade de vida, envolvendo tecnologias da informação e comunicação, o ambiente, as línguas estrangeiras, a cidadania, a higiene e segurança do trabalho, 
bem como o desenvolvimento de iniciativas empresariais. Por sua vez, as competências técnicas são as direcionadas para a aquisição de conhecimentos que forneçam auxílio ao aluno no desenvolvimento profissional. Com base nessas definições, os autores elaboraram o Quadro 2, classificando cada item da Resolução $n^{\circ} .4$ de i3 de julho de 2005, ou como competência transversal, ou como competência técnica. Essa classificação será a adotada para esta pesquisa.

Quadro 2 Classificação das competências existentes na Resolução no .4 de 13 de julho de 2005 em transversais ou técnicas

\section{Competências Transversais}

V Ter iniciativa, criatividade, determinação, vontade política e administrativa, vontade de aprender, abertura às mudanças e consciência da qualidade e das implicações éticas do seu exercício profissional.

II. Desenvolver expressão e comunicação compatíveis com o exercício profissional, inclusive nos processos de negociação e nas comunicações interpessoais ou intergrupais.

IV Desenvolver raciocínio lógico, crítico e analítico para operar com valores e formulações matemáticas presentes nas relações formais e causais entre fenômenos produtivos, administrativos e de controle, bem assim expressando-se de modo crítico e criativo diante dos diferentes contextos organizacionais e sociais.

I. Reconhecer e definir problemas, equacionar soluções, pensar estrategicamente, introduzir modificações no processo produtivo, atuar preventivamente, transferir e generalizar conhecimentos e exercer, em diferentes graus de complexidade, o processo da tomada de decisão.

III Refletir e atuar criticamente sobre a esfera da produção, compreendendo sua posição e função na estrutura produtiva sob seu controle e gerenciamento.

Fonte Fonseca et al. (2007, p.6).

\section{Competências Técnicas}

VI Desenvolver capacidade de transferir conhecimentos da vida e da experiência cotidianas para o ambiente de trabalho e do seu campo de atuação profissional, em diferentes modelos organizacionais, revelando-se profissional adaptável.

VII. Desenvolver capacidade para elaborar, implantar e consolidar projetos em organizações.

VIII Desenvolver capacidade para realizar consultoria em gestão e administração, pareceres e perícias administrativas, gerenciais, organizacionais, estratégicos e operacionais. 
A resolução brasileira não distingue, explicitamente, competência transversal de competência técnica. Porém, em seu Artigo no .5 especifica quais são os conteúdos que moldarão essa formação, dividindo-os em: conteúdos de formação básica, conteúdos de formação específica, conteúdos de estudos quantitativos e conteúdos de formação complementar (FONSECA et al., 2007). Porém, observa-se que as competências listadas pelo MEC, no artigo $4^{\circ}$, da Resolução $n^{\circ}$. 4, de 13 de Julho de 2005 possuem caráter bastante amplo e complexo, sendo transversais a todas as funções da Administração.

Esse conjunto de competências converge para o conceito de recursos de competência preconizados pela escola francesa, por meio do qual o tema é compreendido segundo o alinhamento dos saberes, do saber-fazer e do fazer/ser/agir. Ou seja, o desenvolvimento de competências não é apenas o produto de formação profissional e educacional, ou o conjunto de conhecimentos adquiridos, mas envolve também a habilidade de agir com desenvoltura e flexibilidade, bem como a disposição de passar da percepção para a ação, por meio de respostas confiáveis e rápidas (ALMEIDA; LAGEMANN; SOUSA, 2006). 


\section{METODOLOGIA}

De acordo com Bertero, Caldas e Wood Jr. (2005), o campo de Administração, por ser complexo e muito rico em abordagens, faz com que não haja consenso sobre a maneira de fazer ciência. Em outras palavras, deve haver uma atitude tolerante quanto aos métodos e às abordagens diferentes, pois o campo não comporta apenas uma metodologia ou um paradigma único. Assim, para a realização da pesquisa, optou-se pelo estudo por meio de levantamento de opinião, cuja atenção está voltada para uma situação em particular - a mensuração da qualidade dos serviços educacionais, fundamentados na avaliação das competências adotadas para os cursos de Administração - com base na opinião de um determinado grupo de indivíduos, os estudantes.

Este estudo exploratório e descritivo possibilitou a caracterização, descrição e análise do significado das opiniões dos alunos sobre as competências, veiculadas durante o curso de graduação em Administração e nos cursos de Tecnologia em Gestão, que expressam os efeitos do processo de formação por eles vivenciados (GODOY et al., 2005) e, por meio dessa análise, determinar a qualidade do serviço educacional recebida.

A pesquisa foi dividida em duas fases. Na primeira fase, a pesquisa aborda o método exploratório, que, segundo Aaker, Kumar e Day (200I) e Crano e Brewer (2002), objetiva a descoberta de ideias e dados, assim como a natureza geral do problema e a análise da variável mais relevante do estudo, procurando gerar critérios e compreensão. Para isso, utiliza-se de levantamentos em fontes secundárias, por meio de pesquisas bibliográficas, documentais, de estatísticas e estudos efetuados para o delineamento do problema de pesquisa, bem como para a elaboração do instrumento de coleta de dados. Para o desenvolvimento da escala multi-item, utilizada neste estudo, foi aplicado o roteiro de oito etapas, sugerido por Aaker, Kumar e Day (2004): a) estabelecendo claramente o que se deseja mensurar; b) gerando o maior número de itens possível; c) pedindo a especialistas para avaliar o grupo inicial de itens; d) determinando a escala atitudinal que será utilizada; e) incluindo itens de validação na escala; f) submetendo os itens 
a uma amostra inicial; g) avaliando e aperfeiçoando os itens da escala; e h) otimizando o tamanho da escala. A escala foi posteriormente validada por três especialistas, sendo um com doutorado em Administração, outro com doutorado em Ciências Sociais e o terceiro especialista com doutorado em Educação, em reuniões que ocorreram entre novembro de 2009 e março de 2010.

O questionário foi composto por 46 itens, estruturado com questões fechadas e variáveis quantitativas, com uso de uma escala tipo Likert assim composta: discordo totalmente, discordo bastante, discordo pouco, concordo pouco, concordo bastante e concordo totalmente, de forma a coletar as opiniões dos estudantes acerca das competências recebidas por meio dos serviços educacionais da IEs em estudo. A escala para a avaliação da qualidade dos serviços educacionais com base em competências foi baseada nos critérios propostos pelo Artigo $4^{\circ}$, da Resolução $n^{\circ} .4$, de $\mathrm{I} 3$ de julho de 2005 (Quadro 3). Como explicado por Godoy et al. (2005), esse conjunto de competências é o resultado de discussões entre especialistas no ensino de Administração, que acabaram sendo definidas pelo Conselho Nacional de Educação (CNE), na Resolução no. I, de 2 de fevereiro de 2004, em seu artigo $4^{\circ}$. Esta Resolução acabou sendo revogada posteriormente pela Resolução $n^{\circ} .4$, de 13 de julho de 2005, que manteve, porém, o artigo $4^{\circ}$. A coluna "Dimensão" fornece a nomeação dada, para fins de pesquisa, ao grupo de questões referente a cada item constante na Resolução, para fins de análise.

Quadro 3 Nomes das dimensões do questionário elaborado com base na Resolução no . 4, de 13 de julho de 2005

$\begin{array}{ll}\text { Dimensão } & \begin{array}{l}\text { Artigo } 4^{\circ} \text { - Resolução } n{ }^{\circ} \cdot 4, \\ \text { de } 13 \text { de julho de } 2005\end{array} \\ \text { I. Reconhecer e definir problemas, equacionar } \\ \text { soluções, pensar estrategicamente, introduzir } \\ \text { modificações no processo produtivo, atuar pre- } \\ \text { ventivamente, transferir e generalizar conheci- } \\ \text { mentos, e exercer, em diferentes graus de com- } \\ \text { plexidade, o processo da tomada de decisão. }\end{array}$




\begin{tabular}{|c|c|}
\hline Dimensão & $\begin{array}{l}\text { Artigo } 4^{\circ} \text { - Resolução n }{ }^{\circ} .4 \text {, } \\
\text { de } 13 \text { de julho de } 2005\end{array}$ \\
\hline Expressão e Comunicação & $\begin{array}{l}\text { II. Desenvolver expressão e comunicação com- } \\
\text { patíveis com o exercício profissional, inclusive } \\
\text { nos processos de negociação e nas comunica- } \\
\text { ções }\end{array}$ \\
\hline \multicolumn{2}{|l|}{ interpessoais ou intergrupais. } \\
\hline Atuação Responsável & $\begin{array}{l}\text { III. Refletir e atuar criticamente sobre a esfera } \\
\text { da produção, compreendendo sua posição e } \\
\text { função na estrutura produtiva sob seu controle } \\
\text { e gerenciamento. }\end{array}$ \\
\hline Raciocínio & $\begin{array}{l}\text { IV. Desenvolver raciocínio lógico, crítico e ana- } \\
\text { lítico para operar com valores e formulações } \\
\text { matemáticas presentes nas relações formais e } \\
\text { causais entre fenômenos produtivos, adminis- } \\
\text { trativos e de controle, bem assim expressando- } \\
\text {-se de modo crítico e criativo diante dos diferen- } \\
\text { tes contextos organizacionais e sociais. }\end{array}$ \\
\hline Iniciativa & $\begin{array}{l}\text { V. Ter iniciativa, criatividade, determinação, } \\
\text { vontade política e administrativa, vontade de } \\
\text { aprender, abertura às mudanças e consciência } \\
\text { da qualidade e das implicações éticas do seu } \\
\text { exercício profissional. }\end{array}$ \\
\hline Adaptabilidade & $\begin{array}{l}\text { VI. Desenvolver capacidade de transferir conhe- } \\
\text { cimentos da vida e da experiência cotidianas } \\
\text { para o ambiente de trabalho e do seu campo } \\
\text { de atuação profissional, em diferentes mode- } \\
\text { los organizacionais, revelando-se profissional } \\
\text { adaptável. }\end{array}$ \\
\hline Projetos & $\begin{array}{l}\text { VII. Desenvolver capacidade para elaborar, } \\
\text { implantar e consolidar projetos em organiza- } \\
\text { ções. }\end{array}$ \\
\hline Consultoria & $\begin{array}{l}\text { VIII. Desenvolver capacidade para realizar con- } \\
\text { sultoria em gestão e administração, pareceres e } \\
\text { perícias administrativas, gerenciais, organizacio- } \\
\text { nais, estratégicos e operacionais. }\end{array}$ \\
\hline
\end{tabular}

Na segunda fase do estudo, realizou-se um levantamento do tipo survey, com base em um corte transversal, envolvendo 750 estudantes de cursos presenciais de uma IEs de grande porte, que, para fins de pesquisa, foi denominada de Universidade ALFA (UNIALFA), e que, segundo o MEC/INEP/ DEED (2008), contava com 93.520 alunos, sendo considerada a terceira maior IES do país. A IES tem quatro unidades no município de São 
Paulo (Regiões Oeste, Centro, Norte e Sul) e quatro polos no interior do estado. O levantamento, todavia, foi feito apenas nas unidades situadas na cidade de São Paulo e foram obtidos 629 questionários válidos para análise. A coleta de informações foi superior à amostra mínima considerada satisfatória, para fins de pesquisa, calculada em 560 questionários, com base nas recomendações de Hair Jr. et al. (2005), de que se deve ter pelo menos cinco, mas, de forma ideal, dez respondentes para cada variável a ser analisada. Portanto, 56 variáveis multiplicadas por dez respondentes têm como resultado 560 questionários. Os dados obtidos foram analisados por meio do software SPSS ${ }^{\circledR}$ versão I5.

Para o curso de Bacharelado em Administração, os alunos escolhidos cursavam o $8^{\circ}$ semestre. Nos cursos de Tecnologia de Gestão, os alunos respondentes cursavam o $3^{\circ}$ ou $4^{\circ}$ semestres. A opção de pesquisar alunos do último ano de curso é justificável, pois, para responder à pesquisa, o respondente precisaria ter vivenciado vários aspectos da IES, o que não ocorreria se ele estivesse na fase inicial do curso (ABREU; GUIMARÃes, 2003). Os respondentes foram selecionados por conveniência, e utilizou-se um questionário autoadministrado para levantamento dos dados. 


\section{RESULTADOS E DISCUSSÃO}

As 46 assertivas que compõem a segunda parte do instrumento de pesquisa estão agrupadas em oito dimensões: "Expressão e Comunicação", "Atuação Responsável”, “Tomada de Decisão”, "Raciocínio”, “Iniciativa”, "Adaptabilidade", "Projetos e Consultoria". Cada dimensão refere-se a um parágrafo constante no artigo $4^{\circ}$, da Resolução $n^{\circ} .4$, de I3 de julho de 2005. A análise de cada dimensão foi feita, por sua vez, com base na pontuação e levando-se em consideração se a assertiva foi redigida de maneira positiva e negativa. As afirmações redigidas de forma negativa tiveram o código das questões revertidas, ou seja, o código Discordo Totalmente foi transformado em Concordo Totalmente. O Quadro 4 apresenta as afirmações redigidas de modo negativo e sua posição no questionário.

Quadro 4 Afirmações redigidas de modo negativo

\begin{tabular}{|c|c|}
\hline Questão & $\begin{array}{l}\text { Posição no } \\
\text { Questionário }\end{array}$ \\
\hline 30 importante é agir pensando nos resultados imediatos. & 13 \\
\hline 5 Agir preventivamente atrasa a solução dos problemas do dia a dia. & 01 \\
\hline $\begin{array}{l}7 \text { As decisões devem ser assumidas da mesma forma, } \\
\text { independentemente do nível hierárquico. }\end{array}$ & 29 \\
\hline 7a A tomada de decisão deve ser a mesma, independente da situação que se configura. & 03 \\
\hline 10 Os conceitos aprendidos não contribuíram muito na comunicação entre grupos e pessoas. & 05 \\
\hline 13 Os líderes precisam ser mais intuitivos do que racionais para obter sucesso. & 36 \\
\hline 15a É impossível ao líder ser criativo para adaptar-se às diferentes situações. & 02 \\
\hline 16 Meu curso não me deu bases para ser criativo. & 04 \\
\hline 16a Meu curso não me deu bases para ter pró-atividade. & 18 \\
\hline 16b Meu curso não me deu bases para ser determinado e focado em resultados. & 08 \\
\hline $\begin{array}{l}\text { 16c Meu curso não me deu bases para entender que os } \\
\text { fenômenos administrativos dependem de vontade política. }\end{array}$ & 32 \\
\hline $\begin{array}{l}20 \text { Deve-se produzir produtos com a melhor qualidade possível, independentemente das exigências do } \\
\text { mercado. }\end{array}$ & 21 \\
\hline 20c Cada empresa deve ter sua própria ética. & 06 \\
\hline 21 É impossível usar o que aprendi no meu dia a dia. & 33 \\
\hline 23 É muito difícil usar o conhecimento aprendido no campo profissional. & 41 \\
\hline 27a A maioria dos projetos que as empresas criam não se concretiza. & 35 \\
\hline $\begin{array}{l}28 \text { o campo estratégico não é preocupação para quem ocupa } \\
\text { cargos de nível hierárquico elevado. }\end{array}$ & 46 \\
\hline 28a Só deve participar da estratégia de uma empresa a alta direção. & 20 \\
\hline
\end{tabular}


As tabelas foram elaboradas da seguinte maneira: A coluna de "Respostas Válidas" mostra o número de respostas obtidas para cada item. A coluna "Soma", por sua vez, mostra a somatória dos pontos obtidos dos respondentes. A coluna "Total de Pontos" é elaborada multiplicando-se o total de respostas válidas pelo valor máximo possível para o item, que é 6 . Essa coluna corresponde ao que o MEC identifica como a máxima qualidade esperada do curso de Administração. A coluna "Ponto Médio" é o resultado da coluna “Total de Pontos" dividida por 2, correspondendo a 50\% do máximo de pontos possível. A coluna "Percentual", por sua vez, é o resultado da divisão da pontuação da coluna "Soma" referente às respostas assinaladas em cada assertiva com o "Total de Pontos" válidos de cada assertiva e expressa em percentual.

Em relação aos resultados, se o percentual for de $100 \%$, os estudantes indicam que receberam todas as competências exigidas pelo artigo $4^{\circ}$, da Resolução $\mathrm{n}^{\circ} .4$, de $\mathrm{I} 3$ de julho de 2005 . Se o resultado for abaixo de $50 \%$, tem-se o não atendimento do que é esperado em cada afirmação. Caso o resultado seja de $50 \%$, os estudantes recebem apenas metade do que é determinado pelo MEC. A diferença do quanto falta para 100\% quantifica o não atendimento das exigências do MEC sob o ponto de vista discente, ao mesmo tempo em que determina a qualidade do serviço educacional oferecido.

\section{TOMADA DE DECISÃO}

O primeiro grupo de questões foi batizado de "Tomada de Decisão". Os resultados encontrados para este grupo são mostrados na Tabela 2.

Tabela 2 Tomada de decisão

\begin{tabular}{|c|c|c|c|c|c|}
\hline Assertivas & $\begin{array}{l}\text { Respostas } \\
\text { Válidas }\end{array}$ & Soma & $\begin{array}{l}\text { Total } \\
\text { Pontos }\end{array}$ & $\begin{array}{l}\text { Ponto } \\
\text { Médio }\end{array}$ & $\%$ \\
\hline $\begin{array}{l}\text { I1 Agir preventivamente atrasa a solução dos problemas do } \\
\text { dia a dia. }\end{array}$ & 620 & 2573 & 3720 & 1860 & $69 \%$ \\
\hline $\begin{array}{l}\text { I3 A tomada de decisão deve ser a mesma, independente da } \\
\text { situação que se configura. }\end{array}$ & 613 & 2744 & 3678 & 1839 & $75 \%$ \\
\hline $\begin{array}{l}\text { I10 Aprendi, no meu curso, a buscar aprimoramento contínuo } \\
\text { para o processo produtivo das empresas. }\end{array}$ & 617 & 2708 & 3702 & 1851 & $73 \%$ \\
\hline 113 O importante é agir pensando nos resultados imediatos. & 620 & 1980 & 3720 & 1860 & $53 \%$ \\
\hline
\end{tabular}




\begin{tabular}{|c|c|c|c|c|c|}
\hline Assertivas & $\begin{array}{l}\text { Respostas } \\
\text { Válidas }\end{array}$ & Soma & $\begin{array}{l}\text { Total } \\
\text { Pontos }\end{array}$ & $\begin{array}{l}\text { Ponto } \\
\text { Médio }\end{array}$ & $\%$ \\
\hline $\begin{array}{l}\text { I24 Tudo o que eu aprendi no meu curso pode ser usado nas } \\
\text { empresas. }\end{array}$ & 618 & 2576 & 3708 & 1854 & $69 \%$ \\
\hline $\begin{array}{l}\text { I25 Aprendi no meu curso a fazer comparações e raciocinar } \\
\text { para buscar soluções gerenciais. }\end{array}$ & 617 & 2652 & 3702 & 1851 & $72 \%$ \\
\hline $\begin{array}{l}\text { I27 Antes de agir sempre procuro reconhecer que problema } \\
\text { eu tenho. }\end{array}$ & 618 & 2700 & 3708 & 1854 & $73 \%$ \\
\hline $\begin{array}{l}\text { I29 As decisões devem ser assumidas da mesma forma, } \\
\text { independentemente do nível hierárquico. }\end{array}$ & 620 & 1929 & 3720 & 1860 & $52 \%$ \\
\hline $\begin{array}{l}\text { I38 Com o meu curso ficou mais fácil identificar os problemas } \\
\text { no meu dia a dia. }\end{array}$ & 619 & 2562 & 3714 & 1857 & $69 \%$ \\
\hline
\end{tabular}

As assertivas relativas a esse grupo apresentam-se no ponto médio ou acima dele. Porém, são necessários alguns esclarecimentos. Na afirmação I, que é um item redigido de forma negativa, seria de se esperar que a pontuação fosse mais baixa, ao invés de $69 \%$, pois agir de forma a prevenir problemas está ligado à capacidade de pensar estrategicamente, que é um dos requisitos para a profissão do administrador, e também diminui os problemas do dia a dia. Também é o caso da afirmação 3, pois a tomada de decisão deve levar em consideração a situação que se configura, e não ser independente dela. Esperava-se para essa afirmação uma pontuação mais baixa, ao invés de $75 \%$.

Em relação à afirmação do item I3, também negativa, observa-se que o grau de concordância (53\%) em relação à assertiva tende a predominar. Porém, o ideal é que esse resultado fosse mais baixo, pois leva à conclusão que falta aos estudantes o conhecimento sobre as funções de um administrador, visto que o mesmo não pode agir visando apenas resultados imediatos. No item 29, outro item redigido de forma negativa, a pontuação das respostas (52\%) também é um valor que pode ser considerado baixo, e que deveria ser mais alto, e também revela a falta de conhecimento dos alunos em relação às funções do administrador. Em uma empresa, as decisões são tomadas dentro de níveis hierárquicos, do nível operacional até o nível estratégico, e dessa forma, possuem "pesos" diferentes, pois impactam a organização de forma diferente. 


\section{EXPRESSÃO E COMUNICAÇÃO}

Tabela 3 Expressão e comunicação

\begin{tabular}{|c|c|c|c|c|c|}
\hline Assertivas & $\begin{array}{l}\text { Respostas } \\
\text { Válidas }\end{array}$ & Soma & $\begin{array}{l}\text { Total } \\
\text { Pontos }\end{array}$ & $\begin{array}{l}\text { Ponto } \\
\text { Médio }\end{array}$ & $\%$ \\
\hline $\begin{array}{l}\text { II5 Os conceitos aprendidos não contribuíram muito na comunicação } \\
\text { entre grupos e pessoas. }\end{array}$ & 620 & 2336 & 3720 & 1860 & $63 \%$ \\
\hline $\begin{array}{l}\text { I14 Tudo que aprendo procuro generalizar para poder usar quando } \\
\text { preciso. }\end{array}$ & 620 & 2402 & 3720 & 1860 & $65 \%$ \\
\hline I17 Aprendi a explorar melhor o processo de negociação. & 618 & 2474 & 3708 & 1854 & $67 \%$ \\
\hline II22 Meu curso possibilitou a utilização dos conceitos no meu dia a dia. & 619 & 2674 & 3174 & 1587 & $84 \%$ \\
\hline $\begin{array}{l}\text { II26 Os conceitos aprendidos ficaram mais claros quando os utilizei } \\
\text { em meu trabalho. }\end{array}$ & 615 & 2609 & 3690 & 1845 & $71 \%$ \\
\hline
\end{tabular}

As assertivas relativas a esse grupo apresentam-se acima do ponto médio, indicando que há uma significativa tendência dos alunos de usarem o aprendizado fornecido pela IEs, apesar dos estudantes sugerirem que os conceitos aprendidos não contribuem na melhoria da comunicação entre grupos e pessoas (item $\mathrm{n}^{\circ} .5$, redigido de forma negativa). Esse aspecto da comunicação (interpessoal e intergrupal) precisa, portanto, ser melhorado pela IES, nos cursos oferecidos.

\section{ATUAÇÃO RESPONSÁVEL}

O terceiro grupo de questões foi batizado de "Atuação Responsável”, e seus resultados são mostrados na Tabela 4.

Tabela 4 Atuação responsável

\begin{tabular}{|c|c|c|c|c|c|}
\hline Assertivas & $\begin{array}{l}\text { Respostas } \\
\text { Válidas }\end{array}$ & Soma & $\begin{array}{l}\text { Total } \\
\text { Pontos }\end{array}$ & $\begin{array}{l}\text { Ponto } \\
\text { Médio }\end{array}$ & $\%$ \\
\hline $\begin{array}{l}\text { III11 Ser mais crítico contribuiu para melhorar a qualidade de minhas } \\
\text { decisões. }\end{array}$ & 624 & 2787 & 3744 & 1872 & $74 \%$ \\
\hline $\begin{array}{l}\text { III19 Aprendi a entender quais são os limites de atuação do cargo que } \\
\text { eu ocupo. }\end{array}$ & 618 & 2334 & 3708 & 1854 & $63 \%$ \\
\hline $\begin{array}{l}\text { III23 Meu curso possibilitou perceber a necessidade de ter controle } \\
\text { absoluto das situações empresariais. }\end{array}$ & 615 & 2341 & 3690 & 1845 & $63 \%$ \\
\hline III28 Aprendi a ser mais questionador ao realizar meu trabalho. & 615 & 2686 & 3690 & 1845 & $73 \%$ \\
\hline
\end{tabular}


As assertivas relativas a esse grupo revelam, por meio da somatória dos pontos obtidos, que estão acima do ponto médio. A máxima pontuação obtida foi referente à questão II $(74 \%)$ e a mínima pontuação obtida foi a conseguida pelas questões i9 e 23 (ambas com 63\%). As questões ir e 28 indicam uma tendência ao pensamento reflexivo, o que é uma posição positiva, pois melhora o processo decisório. As questões ig e 23, por sua vez, tratam do conhecimento dos limites do cargo e do controle sobre situações na vida profissional. Essas são dimensões que podem ser melhoradas, apesar de ficarem acima da média de pontos.

\section{RACIOCÍNIO}

O quarto grupo de questões foi batizado de "Raciocínio", e seus resultados são mostrados na Tabela 5.

\section{Tabela 5 Raciocínio}

\begin{tabular}{|c|c|c|c|c|c|}
\hline Assertivas & $\begin{array}{l}\text { Respostas } \\
\text { Válidas }\end{array}$ & Soma & $\begin{array}{l}\text { Total } \\
\text { Pontos }\end{array}$ & $\begin{array}{l}\text { Ponto } \\
\text { Médio }\end{array}$ & $\%$ \\
\hline $\begin{array}{l}\text { IV2. É impossível ao líder ser criativo para adaptar-se às diferentes } \\
\text { situações. }\end{array}$ & 623 & 1623 & 3738 & 1869 & $43 \%$ \\
\hline $\begin{array}{l}\text { IV9. O aspecto mais importante do processo de gestão é a } \\
\text { identificação das causas dos fenômenos administrativos. }\end{array}$ & 618 & 2433 & 3708 & 1854 & $66 \%$ \\
\hline $\begin{array}{l}\text { IV12. O ponto central do meu curso foi o desenvolvimento do } \\
\text { raciocínio analítico. }\end{array}$ & 626 & 2340 & 3756 & 1878 & $62 \%$ \\
\hline $\begin{array}{l}\text { IV15. O meu curso me ensinou a ser criativo para exercer a profissão } \\
\text { de administrador. }\end{array}$ & 620 & 2336 & 3720 & 1860 & $63 \%$ \\
\hline $\begin{array}{l}\text { IV16. Com o meu curso aprendi a buscar soluções que agradam as duas } \\
\text { partes envolvidas em uma transação. }\end{array}$ & 619 & 2482 & 3714 & 1857 & $67 \%$ \\
\hline $\begin{array}{l}\text { IV36. Os líderes precisam ser mais intuitivos do que racionais para } \\
\text { obter sucesso. }\end{array}$ & 615 & 2018 & 3690 & 1845 & $55 \%$ \\
\hline $\begin{array}{l}\text { IV43. Saber matematizar os aspectos administrativos é fundamental } \\
\text { para uma boa gestão. }\end{array}$ & 619 & 2580 & 3714 & 1857 & $69 \%$ \\
\hline
\end{tabular}




\section{INICIATIVA}

O quinto grupo de questões foi batizado de "Iniciativa", cujos resultados são mostrados na Tabela 6.

\section{Tabela 6 Iniciativa}

\begin{tabular}{|c|c|c|c|c|c|}
\hline Assertivas & $\begin{array}{l}\text { Respostas } \\
\text { Válidas }\end{array}$ & Soma & $\begin{array}{l}\text { Total } \\
\text { Pontos }\end{array}$ & $\begin{array}{l}\text { Ponto } \\
\text { Médio }\end{array}$ & $\%$ \\
\hline V4 Meu curso não me deu bases para ser criativo. & 625 & 1728 & 3750 & 1875 & $46 \%$ \\
\hline V6 Cada empresa deve ter sua própria ética. & 623 & 2407 & 3738 & 1869 & $64 \%$ \\
\hline $\begin{array}{l}\text { V8 Meu curso não me deu bases para ser determinado e focado em } \\
\text { resultados. }\end{array}$ & 624 & 1705 & 3744 & 1872 & $46 \%$ \\
\hline V18 Meu curso não me deu bases para ter pró-atividade. & 618 & 1746 & 3708 & 1854 & $47 \%$ \\
\hline $\begin{array}{l}\text { V21 Deve-se produzir produtos com a melhor qualidade possível } \\
\text { independentemente das exigências do mercado. }\end{array}$ & 613 & 2440 & 3678 & 1839 & $66 \%$ \\
\hline V31 Há muitas situações em gestão, em que não se pode ser ético. & 616 & 1741 & 3696 & 1848 & $47 \%$ \\
\hline $\begin{array}{l}\text { V32 Meu curso não me deu bases para entender que os fenômenos } \\
\text { administrativos dependem de vontade política. }\end{array}$ & 613 & 1821 & 3678 & 1839 & $50 \%$ \\
\hline $\begin{array}{l}\text { V37 O líder sempre deve aceitar as novidades no campo da } \\
\text { administração. }\end{array}$ & 618 & 2600 & 3708 & 1854 & $70 \%$ \\
\hline $\begin{array}{l}\text { V39 Desenvolvi com meu curso a vontade de aprender } \\
\text { continuamente. }\end{array}$ & 619 & 2753 & 3714 & 1857 & $74 \%$ \\
\hline
\end{tabular}

O grupo de itens nomeado "Iniciativa" é composto por nove assertivas. Destas, quatro possuem pontuação acima da média, que são os itens 6, 2I, 37 e 39 ( $64 \%, 66 \%, 70 \%$ e $74 \%$, respectivamente), uma (item 32 ) tem desempenho mediano e quatro (itens 4 , 8, I8 e 3I, com respectivamente $46 \%, 46 \%, 47 \%$ e $47 \%$ ). As quatro assertivas que têm desempenho abaixo da média - itens 4 (46\%), 8 (46\%), I8 (47\%), 3I (47\%) - e a afirmação 32, que está na média (50\%), serão analisadas mais detalhadamente.

Nota-se no item 4, negativo, uma tendência dos respondentes a discordar da afirmativa, pois a porcentagem de pontos obtida ficou em $46 \%$. O item 8, também negativo, teve um percentual de $54 \%$ mostrando discordância quanto a essa assertiva. Em relação à afirmativa I8, também uma assertiva negativa, existe discordância, pois o percentual dos pontos obtidos foi de $47 \%$. Para esses três itens era esperado que a discordância fosse ainda maior que a efetivamente demonstrada. $\mathrm{O}$ item 3I, uma assertiva redigida de forma 
positiva, apresentou uma pontuação que resultou em $47 \%$. Essa pontuação deveria ter sido mais baixa. O mesmo acontece em relação ao item 6 , uma afirmativa redigida de forma negativa, com pontuação de $64 \%$. A análise de ambas as assertivas mostra que os alunos acreditam que, às vezes, os negócios não devem ser éticos. Quanto à assertiva 32, negativa, a porcentagem obtida foi de $50 \%$. Também deveria ter uma pontuação menor do que a levantada na pesquisa e revela uma falta de visão para com o papel do administrador, pois a política é uma variável importante nessa profissão.

No geral, os itens 4, 8 e i 8 indicam que o curso poderia ser melhorado para aumentar o desenvolvimento dos discentes tanto em termos profissionais quanto humanos. Por outro lado, as questões 6 e 31, cujo mote é a ética (tanto pessoal quanto empresarial), demonstram que a ideia de ética não é tão clara nos estudantes, pois fica próximo dos 50\%. Quanto às assertivas 37 e 39, as pontuações obtidas indicam um aspecto positivo quanto à formação, com aceitação de novidades ( $70 \%$ dos pontos possíveis) e no estímulo à vontade de aprender continuamente ( $74 \%$ ). A afirmativa 2I, que também é uma assertiva elaborada de forma negativa, demonstra que os estudantes entendem que, para o mercado, a qualidade na elaboração dos produtos é sempre importante, mas sua pontuação deveria ser mais alta do que o resultado de $66 \%$.

\section{ADAPTABILIDADE}

O sexto grupo de questões foi nomeado de "Adaptabilidade", e seus resultados são mostrados na Tabela 7 .

Tabela 7 Adaptabilidade

\begin{tabular}{|c|c|c|c|c|c|}
\hline Assertivas & $\begin{array}{l}\text { Respostas } \\
\text { Válidas }\end{array}$ & Soma & $\begin{array}{l}\text { Total } \\
\text { Pontos }\end{array}$ & $\begin{array}{l}\text { Ponto } \\
\text { Médio }\end{array}$ & $\%$ \\
\hline VI33 É impossível usar o que aprendi no meu dia a dia. & 618 & 1572 & 3708 & 1854 & $42 \%$ \\
\hline $\begin{array}{l}\text { VI40 Com o passar do tempo percebi que é necessário mudar nossa } \\
\text { concepção frente aos novos conhecimentos. }\end{array}$ & 615 & 1483 & 3690 & 1845 & $40 \%$ \\
\hline $\begin{array}{l}\text { VI41 É muito difícil usar o conhecimento aprendido para o campo } \\
\text { profissional. }\end{array}$ & 620 & 1825 & 3720 & 1860 & $49 \%$ \\
\hline $\begin{array}{l}\text { VI26 Os conceitos aprendidos ficaram mais claros quando os utilizei } \\
\text { em meu trabalho. }\end{array}$ & 615 & 2106 & 3690 & 1845 & $57 \%$ \\
\hline
\end{tabular}


Nos itens 33 e 4I, que são afirmações redigidas de forma negativa, pode-se notar, por meio das pontuações obtidas, discordância quanto às afirmações. Ambas as pontuações deveriam ser mais baixas do que se apresentaram. Pode-se inferir que os alunos procuram utilizar os conhecimentos aprendidos no ambiente de trabalho, apesar de as pontuações mostrarem que é possível que uma parcela dos estudantes tenha dificuldades nessa aplicação. Em relação ao item 26, que é uma afirmativa redigida de forma positiva, a porcentagem de $57 \%$ indica uma tendência dos respondentes a concordar que a aplicação dos conceitos melhorou sua compreensão acerca dos mesmos.

O item 40, que é uma afirmativa redigida de forma positiva, mostra que a tendência também é de discordância, com porcentual de $40 \%$. Esperavase uma pontuação mais alta para essa afirmação. Isso demonstra uma falta de visão em relação aos papéis do administrador, que necessita possuir abertura a mudanças para melhor desempenho de suas funções. Pode-se concluir que a IEs não está, nesse quesito, cumprindo seu papel de formar profissionais abertos e capazes de adaptação frente a novos conhecimentos.

\section{PROJETOS}

O sétimo grupo de questões foi nomeado de "Projetos", cujos resultados podem ser visualizados na Tabela 8 .

\section{Tabela 8 Projetos}

\begin{tabular}{|c|c|c|c|c|c|}
\hline Assertivas & $\begin{array}{l}\text { Respostas } \\
\text { Válidas }\end{array}$ & Soma & $\begin{array}{l}\text { Total } \\
\text { Pontos }\end{array}$ & $\begin{array}{l}\text { Ponto } \\
\text { Médio }\end{array}$ & $\%$ \\
\hline VII7 Elaborar relatórios é uma coisa que aprendi. & 617 & 2178 & 3702 & 1851 & $59 \%$ \\
\hline VII30 Desenvolvi a capacidade de implantar planos. & 615 & 2417 & 3690 & 1845 & $66 \%$ \\
\hline VII34 Meu curso deu uma grande ênfase em gestão de projetos. & 616 & 2122 & 3696 & 1848 & $57 \%$ \\
\hline VII35 A maioria dos projetos que as empresas criam não se concretiza. & 618 & 1962 & 3708 & 1854 & $53 \%$ \\
\hline
\end{tabular}

A pontuação referente às respostas dadas ao item 35 (53\%) indica uma tendência à concordância em relação a essa afirmação, sendo uma afirmativa redigida de forma negativa. O mesmo ocorre em relação ao item 30, com 
$66 \%$ dos pontos. E no item 34, o porcentual de 57\% indica concordância quanto aos cursos enfatizarem gestão de projetos. Ao se analisar conjuntamente essas três assertivas, pode-se concluir que os alunos acham que possuem a habilidade para elaborar e implantar projetos, mas na realidade não a possuem.

\section{CONSULTORIA}

O oitavo e último grupo de questões foi nomeado de "Consultoria”, e seus resultados podem ser observados na Tabela 9.

Tabela 9 Consultoria

\begin{tabular}{|c|c|c|c|c|c|}
\hline Assertivas & $\begin{array}{l}\text { Respostas } \\
\text { Válidas }\end{array}$ & Soma & $\begin{array}{l}\text { Total } \\
\text { Pontos }\end{array}$ & $\begin{array}{l}\text { Ponto } \\
\text { Médio }\end{array}$ & $\%$ \\
\hline $\begin{array}{l}\text { VIII46 O campo estratégico não é preocupação para quem ocupa } \\
\text { cargos de nível hierárquico elevado. }\end{array}$ & 618 & 1605 & 3708 & 1854 & $43 \%$ \\
\hline $\begin{array}{l}\text { VIII45 Realizar análise e dar parecer no campo gerencial é uma das } \\
\text { atividades que os cursos de administração possibilitam aos alunos. }\end{array}$ & 617 & 2474 & 3702 & 1851 & $67 \%$ \\
\hline VIII44 Emitir pareceres gerenciais é diferente de dar opinião. & 617 & 2564 & 3702 & 1851 & $69 \%$ \\
\hline VIII20 Só deve participar da estratégia de uma empresa a alta direção. & 617 & 1559 & 3702 & 1851 & $42 \%$ \\
\hline $\begin{array}{l}\text { VIII42 Meu curso deu uma grande ênfase para o desenvolvimento de } \\
\text { conhecimentos, para que eu possa prestar consultoria. }\end{array}$ & 615 & 2155 & 3690 & 1845 & $58 \%$ \\
\hline
\end{tabular}

As assertivas de números 46 e 20 foram redigidas de forma negativa e tiveram suas pontuações invertidas para fins de análise. No item 46, a porcentagem de $43 \%$ indica que os respondentes discordam da afirmação. O mesmo acontece em relação à assertiva 20 com $42 \%$ de pontuação. Porém, em ambos os casos o ideal é que a pontuação desses dois itens fosse ainda mais baixa. Pode-se inferir que a concepção da estratégia como competência dos gestores deve ser mais bem sedimentada nos alunos. 


\section{CONSIDERAÇÕES FINAIS}

A perspectiva do aluno permite considerações acerca de dois aspectos: o propósito do trabalho de cooperar para as atividades de formação em Gestão e Administração (COSTA; OLIVeira 2008) e por permitir levantar informações sob o ponto de vista discente, ao invés de privilegiar a opinião de gestores e docentes (GODOY et al., 2005).

A avaliação da qualidade percebida, pela ótica do estudante, dos serviços educacionais é uma importante ferramenta para a determinação da opinião destes nas IES, pois pode criar uma vantagem competitiva ao adotar como estratégia a melhoria dos serviços (FIRDAUs, 2006a). Assim, ao avaliar se o atributo "competências", necessário para o exercício profissional nos cursos de Administração e Gestão, está sendo transmitido aos discentes, a IES pode tomar ações pertinentes para elevar o nível do desempenho do serviço educacional prestado, aumentando sua competitividade perante a concorrência, gerando satisfação nos alunos e contribuindo para o desenvolvimento da sociedade como um todo.

Selembrarmos que no Brasil, em 2008, existiam 2.252 IEs em funcionamento, a adequação dos cursos visando ao aumento da empregabilidade de seus estudantes pode ser um importante diferencial competitivo nesse ambiente. Com o objetivo de contribuir para a melhoria dos serviços educacionais, tomando-se como parâmetro as Diretrizes Curriculares Nacionais, buscouse avaliar se os cursos oferecidos pela IEs em estudo convergiam, na opinião dos estudantes, às competências requeridas pelo $\mathrm{MEC}$, por meio da Resolução $\mathrm{n}^{\mathrm{o}} 4$, de $\mathrm{I} 3$ de julho de 2005 (MEC/CNE/CES, 2005). A qualidade dos cursos pesquisados seria, portanto, baseada nessa convergência.

Ao se procurar responder se "A qualidade do serviço educacional pode ser avaliada com base nas competências individuais exigidas para o exercício da profissão de administrador?”, pode-se concluir ser possível, tomandose por base o referencial teórico, sobretudo observando-se os parâmetros das Diretrizes Curriculares nacionais; entretanto, não foi possível tal constatação na pesquisa de campo realizada.

O conjunto de competências, constantes no Artigo $4^{\circ}$, da Resolução n ${ }^{\circ}$. 4, de I3 de julho de 2005, foram classificadas em dois grupos: competências 
transversais (que envolve as dimensões: Tomada de Decisão, Expressão e Comunicação, Atuação responsável, Raciocínio e Iniciativa) e competências técnicas (Adaptabilidade, Projetos e Consultoria). Das 28 afirmações redigidas de modo positivo, 26 têm pontuações cujos resultados equivalem à faixa que vai de $57 \%$ a $84 \%$ do total de pontos, o que indica que os alunos recebem, porém não em sua totalidade, as competências exigidas pelo MEC. Duas afirmações redigidas de forma positiva, de números 3I e 40, tiveram desempenho inferior a 50\%, mostrando que os estudantes têm pouca adaptabilidade frente a novos conhecimentos (item 40) e têm uma noção pouco clara sobre a ética nos negócios (item 3I). Em relação aos itens redigidos de forma negativa, em um total de 18 afirmações, a faixa de respostas ficou entre $42 \%$ e $69 \%$, que, na maioria das afirmações, deveriam ter tido como respostas pontuações mais baixas do que as que foram obtidas. A exceção seria o item 2I, que trata da qualidade dos produtos, e que deveria ter tido uma pontuação maior que os $66 \%$ obtidos.

Pode-se concluir, levando-se em consideração os resultados terem caráter exploratório, em função das características da amostra calculada e escolhida por conveniência, que a qualidade percebida pelos estudantes com relação aos serviços educacionais prestados na IEs pesquisada, com base na Resolução $n^{\circ} 4$ de 13 de julho de 2005 (MEC/CNE/CES, 2005) não está totalmente em conformidade com o que a norma exige, pois as pontuações ficaram abaixo do score máximo possível. Porém, de forma geral, o resultado final pode ser considerado positivo, apesar da existência de diversos aspectos que necessitam ser melhorados. Deve ser ressalvado que, embora a opinião dos estudantes seja importante para a avaliação do ensino ministrado, isso não significa que eles tenham o conhecimento necessário para avaliar se o ensino recebido está de acordo ou não com as exigências do MEC.

Esta qualidade percebida, observada na pesquisa de campo, pode ser relacionada com a afirmação de Sampaio (2000), sobre a expansão no ensino superior, Além disso, o termo competência foi utilizado aqui de forma ampla, pois um exame rigoroso dos itens que compõem o instrumento de coleta de dados deixa antever a adoção indistinta de competências, habilidades e atitudes. Isso acontece porque mesmo na Resolução n ${ }^{\circ}$. 4, de 
I3 de julho de 2005, nota-se uma certa confusão na adoção dos conceitos de competências e habilidades, não se fazendo clara a distinção entre eles (GODOY et al., 2005).

Por outro lado, a importância dos resultados aumenta, em um momento em que proliferam debates relativos à rediscussão do papel do Estado no ensino superior (DOURADO, 2002), a discussão sobre os sistemas de avaliação da educação superior brasileira (ABREU JÚNIOR, 2009) e também as discussões sobre o que seria a qualidade em educação superior (PEREIRA, 2004; BERTOLIN, 2009). Em relação aos cursos de formação em Administração e Gestão, essas questões encontram-se ainda mais em evidência, em virtude da expansão dos cursos de graduação e pós-graduação em gerenciamento no Brasil, e das dúvidas quanto à formação dos futuros profissionais dessas áreas (NICOLINI, 2003).

Sugere-se, para possíveis estudos, a validação estatística da escala desenvolvida. Outra possibilidade de pesquisa é a aplicação da escala apenas para estudantes de Administração, ou apenas para alunos dos cursos de Gestão. Pode-se também verificar se há diferenças entre as opiniões dos estudantes de Administração e de Gestão.

Quanto às limitações da pesquisa, deve-se observar que a delimitação da investigação a uma única IEs, mesmo de grande porte, não possibilita inferências para outras organizações de mesma natureza. Além disso, há o viés pessoal do investigador, presente tanto na condução da pesquisa quanto na análise dos dados e em seus resultados, e que deve ser levado em consideração para efeito de aceitação e discussão das conclusões. Outra limitação a ser levada em consideração decorre da amostra, além de ser intencional, ser composta de alunos de Administração e de Tecnologia, porém sem fazer diferenciação entre os alunos de ambos os cursos, que possuem perfis diferentes, o que pode influenciar os resultados em função da utilização de dados agregados. Também se deve levar em consideração que a abrangência e a complexidade do tema estudado conferem uma profundidade e abrangência que não foi totalmente compreendida ou capturada nesta pesquisa, deixando escapar nesta abordagem diversos elementos que poderiam validar, completar ou mesmo contrastar as 
conclusões alcançadas. Porém, o objetivo de interesse imediato é a obtenção de informações críveis que favoreçam ou ajudem a esclarecer estudos posteriores. As limitações da pesquisa, embora existam, não invalidam os resultados da investigação, que ajudou a contribuir para o desenvolvimento de pesquisas na área (TELLES, 1997). 


\section{REFERÊNCIAS}

AAKER, D; KUMAR, V; DAY, G. Pesquisa de Marketing. São Paulo: Atlas, 2001.

AAKER, D; KUMAR, V; DAY, G. Pesquisa de Marketing. 2.ed. São Paulo: Atlas, 2004. ABREU JÚNIOR, N. Sistema(s) de Avaliação da Educação Superior Brasileira. Cad. CEDES, Campinas, v. 29, n. 78, 2009.

ABREU, M. F. D. V; GUIMARÃES, T. A. Satisfação com o Ensino Superior em Administração: O Ponto de Vista de discentes de IES Privadas do Distrito Federal. In: ENCONTRO NACIONAL DOS PROGRAMAS DE PÓS-GRADUAÇÃO EM ADMINISTRAÇÃO, 27., 2003, Atibaia. Anais... Atibaia, ENANPAD, 2003.

ALL CONSULTING. Estudo Setorial do Ensino Superior. São Caetano do Sul, 2009.

ALMEIDA, D. R.; LAGEMANN, L.; SOUSA, S. V. A. A Importância do Estágio Supervisionado Para a Formação do Administrador. In: ENCONTRO NACIONAL DOS PROGRAMAS DE PÓS-GRADUAÇÃO EM ADMINISTRAÇÃO, 30., 2006, Salvador. Anais... Salvador, ENANPAD, 2006.

ANDRADE, R. O. B; AMBONI, N. Projeto Pedagógico para Cursos de Administração. São Paulo: Makron Books, 2002.

BERTERO, C.O. Ensino e Pesquisa em Administração. São Paulo:

Thomson Learning, 2006.

BERTERO C.O.; CALDAS, M. P.; WOOD JR., T. Produção Científica em Administração no Brasil: O Estado-da-Arte. São Paulo: Atlas, 2005.

BERTOLIN, J. C. G. Qualidade em Educação Superior: da Diversidade de Concepções à Inexorável Subjetividade Conceitual. Avaliação, v. 14, n.1, p.127-149, 2009.

BOTERF, G. De La Compétence. Paris: Les Editions d'Organisation, 1995.

CNE/CES (2001). Conselho Nacional de Educação - Câmara de Educação Superior. Parecer CNE/CES 436 de 6 de abril de 2001. Disponível em: <http://portal.mec.gov.br/ cne/arquivos/pdf/CES0436.pdf>. Acesso em: 20/07/2010.

CNE/CP (2002). Conselho Nacional de Educação - Conselho Plano. Resolução CNE/CP 3, de 18 de dezembro de 2002. Disponível em: <http://portal.mec.gov.br/cne/arquivos/pdf/ CP032002.pdf $>$. Acesso em: 20/07/2010.

COSTA, F. J; OLIVEIRA, L. G. L. Formação em Administração na Perspectiva do Aluno: Valor Percebido no Curso, Percepção do Prestígio e Identificação com a Profissão. Revista de Administração da Universidade Federal de Santa Maria.

Santa Maria (RS), v.1, n. 3, p. 453-468, 2008.

CRANO, W. D; BREWER, M. B. Principles and Methods of Social Research. New Jersey: LEA; 2002.

CRONIN, J. J; TAYLOR, S. A. Measuring Service Quality: A Reexamination and Extension. Journal of Marketing, v. 56, n.1, p.55 - 68, 1992. 
DAVEL, E.; VERGARA, S.; GHADIRI, S.; FISCHER, T. Revitalizando a Relação Ensino-Aprendizagem em Administração Por Meio de Recursos Estéticos. In: ENCONTRO NACIONAL DOS PROGRAMAS DE PÓS-GRADUAÇÃO EM ADMINISTRAÇÃO, 28., Curitiba.. Anais... ENANPAD, 2004.

DELORS, J. Educação um Tesouro a descobrir. Relatório para a UNESCO da Comissão Internacional sobre Educação para o século XXI. São Paulo: Cortez, UNESCO e MEC, 1998.

DOURADO L. F. Reforma do Estado e as Políticas Públicas para a Educação Superior no Brasil nos Anos 90. Educação \& Sociedade, v. 13, n.80, p. 234-252, 2002.

FUNDAÇÃO DE AMPARO À PESQUISA DO ESTADO DE SÃO PAULO (FAPESP). Indicadores de Ciência, Tecnologia e Inovação em São Paulo, 2001.

FIRDAUS, A. Measuring Service Quality in Higher Education HEdPERF versus SERVPERF. Marketing Intelligence \& Planning, v.24, n.1, November, 2006a, p. 31-47.

FIRDAUS, A. The Development of HEdPERF: A New Measuring Instrument of Service Quality For The Higher Education Sector. International Journal of Consumer Studies, v. 30, n.6, November, 2006b, p. 569-581.

FONSECA, J. S. P.; MAGINA, S. M. P.; BRAGA, E.; OLIVEIRA, I. M. M. A Influência da Formação em Administração nas Habilidades e Competências do Administrador (Futuro e Atual). In: ENCONTRO NACIONAL DOS PROGRAMAS DE PÓS-

GRADUAÇÃO EM ADMINISTRAÇÃO, 31., 2007, Rio de Janeiro. Anais... ENANPAD, 2007.

GODOY, A. S.; SANTOS, N. J.; FORTE, D.; FILHO, A. F. C.; GHOBRIL, A. N.; MASMO, P. L. Competências Adquiridas Durante os Anos de Graduação: Um Estudo de Caso a Partir das Opiniões dos Alunos Formandos de um Curso de Administração de Empresas. In: ENCONTRO NACIONAL DOS PROGRAMAS DE PÓSGRADUAÇÃO EM ADMINISTRAÇÃO, 29., Brasília.. Anais... ENANPAD, 2005.

HAIR Jr., J. F; ANDERSON, R.E; TATHAM, R.L; BLACK, W.C. Análise Multivariada de Dados. 5.ed. Porto Alegre: Bookman, 2005.

IBGE. Instituto Brasileiro de Geografia e Estatística. Projeção da População do Brasil por sexo e idade: 1980-2050 - Revisão 2008.

IBGE. Instituto Brasileiro de Geografia e Estatística. Censo 2010.

KERLINGER, F. N. Metodologia da Pesquisa em Ciências Sociais: um tratamento conceitual. São Paulo: EPU: EDUSP, 1980.

LEITE, P. A Passos Lentos. Revista Ensino Superior. 145 ed. São Paulo (SP): Segmento, 2010.

MACCARI, E.A.; LIMA, M.C.; RICCIO, E.L. Uso do Sistema de Avaliação por Programas na Área de Administração no Brasil. In: ENCONTRO NACIONAL DOS PROGRAMAS DE PÓS-GRADUAÇÃO EM ADMINISTRAÇÃO, 33., São Paulo. Anais... ENANPAD, 2009. 
MEC/CNE/CES. Ministério da Educação e Cultura / Conselho Nacional de Educação/ /Câmara de Educação Superior. Resolução nº. 4, de 13 de julho de 2005.

MEC/INEP/DEED. Ministério da Educação / Instituto Nacional de Estudos e Pesquisas Educacionais Anísio Teixeira / Diretoria das Estatísticas Educacionais. Sinopse Estatística da Educação Superior, 1999 - Parte 1. Disponível em: $<$ http://portal.inep.gov.br/superior-censosuperior-sinopse>. Acesso em: 10/04/2010.

MEC/INEP/DEED. Ministério da Educação / Instituto Nacional de Estudos e Pesquisas Educacionais Anísio Teixeira / Diretoria das Estatísticas Educacionais. Sinopse Estatística da Educação Superior, 2008 (Versão Preliminar Publicada em 27 de novembro de 2009).

NICOLINI, A. M. Qual Será o Futuro das Fábricas de Administradores? Revista de Administração de Empresas - RAE. São Paulo: FGV, v. 43, n.2, p. 44-54, 2003.

NUNES, S. C.; PATRUS-PENA, R.; DANTAS, D. C. Do Projeto Pedagógico ao Desenvolvimento de Competências no Curso de Administração: O Processo de Ensino Aprendizagem Sob o Olhar do Aluno. In: ENCONTRO NACIONAL DOS PROGRAMAS DE PÓS-GRADUAÇÃO EM ADMINISTRAÇÃO, 35., Rio de Janeiro. Anais... 2011.

PARASURAMAN, A; BERRY, L. L; ZEITHAML, V. A. SERVQUAL: A Multiple-Item Scale for Measuring Consumer Perceptions of Service Quality. Journal of Retailing, v. 64, n.1, p.12-40, 1988.

PEREIRA, R. S. Evolução Qualitativa na Educação Superior. In Oliveira, O. J. (Org.). Gestão da Qualidade: Tópicos Avançados. São Paulo: Cengage Learning, 2004, p. 225 237.

RUAS, R. Mestrado Modalidade Profissional: Em Busca da Identidade. Revista de Administração de Empresas, v. 43, n. 2, p. 55-63, 2003.

SAMPAIO, H. Ensino Superior no Brasil - O Setor Privado. São Paulo: Hucitec - Fapesp, 2000.

SOUKI, G.Q; GONÇALVES FILHO, C.; SILVA, G. M. A. Perceived Quality, Attitudes and Behaviour Intentions of the Customers: An Empiric Study in Brazil. In: International European Operations Management Association Conference - EUROMA 2006, Glasgow, 2006.

SOUKI, G.Q; NETO, J.B. Desenvolvimento de uma Escala para Avaliação da Qualidade Percebida por Estudantes de Ensino Médio. In: ENCONTRO NACIONAL DOS PROGRAMAS DE PÓS-GRADUAÇÃO EM ADMINISTRAÇÃO, 31., Rio de Janeiro. Anais... ENANPAD, 2007.

SOUKI, G.Q; PEREIRA, C.A. Satisfação, Motivação e Comprometimento de Estudantes de Administração: Um Estudo com Base nos Atributos de uma Instituição Superior. In: ENCONTRO NACIONAL DOS PROGRAMAS DE PÓS-GRADUAÇÃO EM ADMINISTRAÇÃO, 28., Curitiba. Anais... ENANPAD, 2004. 
TELLES, R. Sistema de Informações Gerenciais de Mercado - Uma Contribuição ao Entendimento da Compreensão do Mercado dos Diferentes Níveis Administrativos de uma Organização - Um Estudo Exploratório em uma Organização Industrial Privada. 1997. 205 f. Dissertação (Mestrado em Administração) - Universidade de São Paulo USP - São Paulo.

VALENTIM, L. M. O.; ALMEIDA, S. F.; SILVA, W. R.; ALMEIDA, P. L. P. Diagnóstico do Curso de Administração da Universidade Federal de Campina Grande - PB. In: XI SEMEAD - Seminários em Administração, 11., São Paulo. Anais... SEMEAD, 2008.

VELUDO-DE-OLIVEIRA, T. M; IKEDA, A. A. Valor em Serviços Educacionais. RAE Eletrônica, v. 5, n. 2, 2006.

VERGARA, S. C. Métodos de Pesquisa em Administração. São Paulo: Atlas, 2005.

ZEITHAML, V. A. Consumer Perceptions of Price, Quality and Value: A Means-End Model and Synthesis of Evidence. Journal of Marketing, v. 52, n. 1, p. 2-22, 1988. 


\section{DADOS DOS AUTORES}

ALEXANDRE MENDES DA SILVA^alex_ams1972@yahoo.com.br Mestre em Administração pela Universidade de São Caetano do Sul Instituição de vinculação: Universidade Nove de Julho São Paulo/SP - Brasil

Áreas de interesse em pesquisa: Administração.

^Endereço: Rua Vergueiro, $n^{\circ} 235$

Liberdade São Paulo/SP 01504-000

RAQUEL DA SILVA PEREIRA raquelspereira@uol.com.br

Doutora em Ciências Sociais pela PUC/SP

Instituição de vinculação: Universidade Municipal de São Caetano do Sul São Caetano do Sul/SP - Brasil

Áreas de interesse em pesquisa: Administração, Educação Superior, Gestão

Socioambiental. 